\title{
Novel Metal(II) Complexes with Bidentate Schiff Base Ligand: Synthesis, Spectroscopic Properties and Dye Decolorization Functions
}

\author{
C. KARAKAyA ${ }^{a}$, B. Dede ${ }^{b, *}$ And E. CiceK ${ }^{c}$ \\ ${ }^{a}$ Faculty of Engineering, Celal Bayar University, Manisa, Turkey \\ ${ }^{b}$ Faculty of Science and Art, Süleyman Demirel University, Isparta, Turkey \\ ${ }^{c}$ Faculty of Science and Art, Mehmet Akif Ersoy University, Burdur, Turkey
}

\begin{abstract}
The bidentate Schiff base ligand 4-chloro-2-[1-(4-phenylphenyl)ethylideneaminolphenol and its mononuclear $\mathrm{Co}(\mathrm{II}), \mathrm{Ni}(\mathrm{II}), \mathrm{Cu}(\mathrm{II})$ and $\mathrm{Zn}(\mathrm{II})$ complexes have been synthesized. Ligand and metal complexes were characterized by elemental analyses, magnetic susceptibility, molar conductivity, ${ }^{1} \mathrm{H}$ - and ${ }^{13} \mathrm{C}-\mathrm{NMR}$, the Fourier transform infrared, UV-Vis, inductively coupled plasma optical emission spectrometry, and thermogravimetric-differential thermogravimetric studies. The results suggest that the mononuclear complexes have a metal to ligand mole ratio of $1: 2$ and the metal(II) ions are coordinated with the phenolic oxygen and imine nitrogen atoms. Octahedral structures are proposed for the complexes of the Schiff base ligand. Furthermore, the complexes were checked for their efficiency to decolorize the dye methylene blue. In our experiments we found that metal(II) complexes had an acceptable decolorization efficiency against the dye methylene blue.
\end{abstract}

DOI: 10.12693/APhysPolA.129.208

PACS: 81.20.Ka, 82.80.-d, 89.60.-k

\section{Introduction}

The Schiff bases can be formed by the condensation of a primary amine with a carbonyl compound and they contain an azomethine group $(-\mathrm{CH}=\mathrm{N}-)$. The Schiff bases are usually bi- or tri-dentate ligands capable of forming stable transition metal complexes. The chemistry of the metal complexes of the Schiff bases containing nitrogen and other donor atoms has attracted a great deal of attention due to their stability, biological activity [1], and potential applications in many fields such as oxidation catalysis [2], electrochemistry [3], etc. Therefore synthesis of new Schiff bases and their metal complexes has been still the aim of many recent investigations. Transition metal complexes have been also used for degradation of the toxic dyes produced during dye production and textile manufacturing processes [4]. Due to the stability of modern textile dyes, conventional biological treatment methods are ineffective for their degradation $[5,6]$.

In the present work, we have synthesized a new bidentate Schiff base ligand (HL) using biphenyl as a starting material. Then, its $\mathrm{Co}(\mathrm{II}), \mathrm{Ni}(\mathrm{II}), \mathrm{Cu}(\mathrm{II})$ and $\mathrm{Zn}(\mathrm{II})$ complexes were obtained by the reaction of HL and appropriate metal salts. All of the synthesized compounds were characterized using several analytical and spectroscopic techniques. Additionally dye decolorization properties of the metal complexes were studied in detail.

*corresponding author; e-mail: bulentdede@sdu.edu.tr

\section{Experimental}

\subsection{Material}

All the solvents and the other chemicals used were of reagent grade and used as received.

\subsection{Spectral measurements}

Melting points were determined in open capillaries on an IA 9100 Electrothermal apparatus. Elemental analyses $(\mathrm{CHN})$ were performed in a LECO 932 CHNS analyzer and metal contents of the complexes were determined by a Perkin-Elmer Optima 5300 DV ICPOES spectrometer. ${ }^{1} \mathrm{H}$ - and ${ }^{13} \mathrm{C}-\mathrm{NMR}$ spectra were recorded with a Bruker AVANCE $300 \mathrm{MHz}$ spectrometer in DMSO- $d_{6}$ with reference to $\mathrm{Me}_{4} \mathrm{Si}(0.0 \mathrm{ppm})$. IR spectra were obtained on a Shimadzu IRPrestige-21 FT-IR spectrophotometer with samples prepared as $\mathrm{KBr}$ pellets with $2 \mathrm{~cm}^{-1}$ resolution. Spectrophotometric measurements were performed on a PG T80 + spectrophotometer. Molar conductivities of the metal complexes were determined in dry DMF at room temperature using a Optic Ivymen System conductivity meter. Thermal analyses of metal complexes were carried out in atmospheric air using a Perkin Elmer Diamond TGA thermal analyzer. Magnetic susceptibilities of the complexes were measured by the Gouy method at room temperature using a model Sherwood Scientific MX1.

\subsection{Synthesis of ligand (HL)}

4-acetylbiphenyl was synthesized by the FriedelCrafts acylation reaction of biphenyl with acetyl chloride in the 1:1 mole ratio according to literature method [7]. The Schiff base namely, 4-chloro-2-[1(4-phenylphenyl)ethylideneaminolphenol was prepared 
by refluxing a mixture of equimolar quantities of 4-acetylbiphenyl with 2-amino-4-chloro phenol in absolute ethanol. The product was filtered off, washed with diethyl ether and dried over $\mathrm{P}_{2} \mathrm{O}_{5}$.

\subsection{Synthesis of complexes [ $\left.\mathrm{ML}_{2}\left(\mathrm{H}_{2} \mathrm{O}\right)_{2}\right]$ [M: $\mathrm{Co}(\mathrm{II})$, $\mathrm{Ni}(I I), \mathrm{Cu}(\mathrm{II})$ and $\mathrm{Zn}(\mathrm{II})]$}

$2 \mathrm{mmol}$ of 4-chloro-2-[1-(4-phenylphenyl)ethylideneaminolphenol dissolved in methanol was mixed with $\mathrm{Et}_{3} \mathrm{~N}(2 \mathrm{mmol})$ and stirred for $0.5 \mathrm{~h}$. Methanolic solution of metal acetates of $\mathrm{Co}(\mathrm{II}), \mathrm{Ni}(\mathrm{II}), \mathrm{Cu}(\mathrm{II})$, and $\mathrm{Zn}(\mathrm{II})$ ( $1 \mathrm{mmol})$ were added to the hot methanolic solution of the resulting solution which resulted in the precipitation of metal derivatives. The resulting mixture was refluxed for $2 \mathrm{~h}$. The product was filtered off, washed with ethanol and diethyl ether and then dried over $\mathrm{P}_{2} \mathrm{O}_{5}$.

\subsection{Dye decolorization studies}

A $150 \mathrm{~mL}$ round-bottom flask containing a $100 \mathrm{~mL}$ solution of the methylene blue in water $(50 \mathrm{mg} / \mathrm{L})$ and complex $(1,2,3$ or 4$)$ (100 $\mathrm{mg}$ ) was placed in a water bath $\left(25^{\circ} \mathrm{C}\right)$. While the solution was stirred, $15 \mathrm{~mL}$ $\mathrm{H}_{2} \mathrm{O}_{2}(30 \%$, v:v) was added into it and the solution was stirred for $2 \mathrm{~h}$. The absorbances were measured in a spectrophotometer at the maximum wavelength for the methylene blue $(662 \mathrm{~nm})$. The decolorization rate of the dye was determined as expressed in Eq. (1):

dye decolorization $\%=\left[\left(A_{0}-A_{t}\right) / A_{0}\right] \times 100$,

where $A_{t}$ is the absorbance at requested time and $A_{0}$ is the initial absorbance of each solution.

\section{Results and discussion}

Preparation of the Schiff base ligand was performed in two steps from biphenyl as shown below.
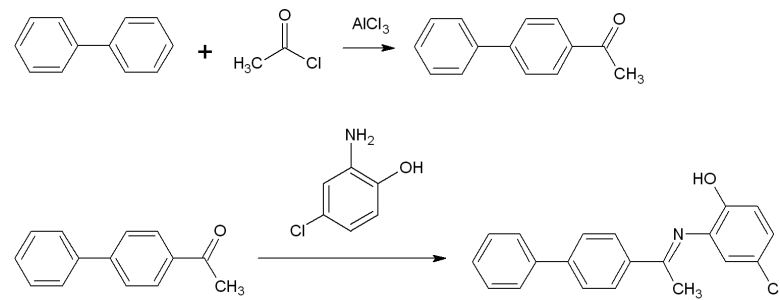

4-acetylbiphenyl was prepared from acetyl chloride and biphenyl by the Friedel-Crafts acylation in the presence of aluminium chloride [7]. Condensation of the 4-acetylbiphenyl with 2-amino-4-chloro phenol gave the Schiff base ligand. The analytical and physical data of the ligand and its mononuclear complexes are given in Table I. The analytical data indicated that the metal to ligand ratio is $1: 2$ for the complexes.

TABLE I

Physical properties and elemental analysis of the ligand and its metal complexes.

\begin{tabular}{c|c|c|c|c|c|c|c|c|c}
\hline \hline Compound & $\begin{array}{c}\mu_{\text {eff }} \\
{\left[\mu_{\mathrm{B}}\right]}\end{array}$ & $\Lambda_{\mathrm{M}}^{a}$ & Color & $\begin{array}{c}\text { m.p. } \\
{\left[{ }^{\circ} \mathrm{C}\right]}\end{array}$ & $\begin{array}{c}\text { Yield } \\
{[\%]}\end{array}$ & \multicolumn{4}{|c}{ Calculated (found) [\%] } \\
\cline { 6 - 10 } $\mathrm{HL}$ & - & - & yellow & $240^{b}$ & 65 & $\begin{array}{c}74.65 \\
(74.51)\end{array}$ & $\begin{array}{c}5.01 \\
(5.43)\end{array}$ & $\begin{array}{c}4.35 \\
(4.21)\end{array}$ & - \\
\hline $\begin{array}{c}(1) \\
\mathrm{CoL}_{2}\left(\mathrm{H}_{2} \mathrm{O}\right)_{2}\end{array}$ & 3.80 & 16 & brown & $260^{b}$ & 56 & $\begin{array}{c}65.23 \\
(65.56)\end{array}$ & $\begin{array}{c}4.65 \\
(4.57)\end{array}$ & $\begin{array}{c}3.80 \\
(3.57)\end{array}$ & $\begin{array}{c}8.00 \\
(8.12)\end{array}$ \\
\hline $\begin{array}{c}(2) \\
\mathrm{NiL}_{2}\left(\mathrm{H}_{2} \mathrm{O}\right)_{2}\end{array}$ & 2.88 & 16 & brown & $267^{b}$ & 44 & $\begin{array}{c}65.25 \\
(65.04)\end{array}$ & $\begin{array}{c}4.65 \\
(4.43)\end{array}$ & $\begin{array}{c}3.80 \\
(3.63)\end{array}$ & $\begin{array}{c}7.97 \\
(7.81)\end{array}$ \\
\hline $\begin{array}{c}(3) \\
\mathrm{CuL}_{2}\left(\mathrm{H}_{2} \mathrm{O}\right)_{2}\end{array}$ & 1.77 & 17 & black & $208^{b}$ & 48 & $\begin{array}{c}64.82 \\
(64.49)\end{array}$ & $\begin{array}{c}4.62 \\
(4.51)\end{array}$ & $\begin{array}{c}3.78 \\
(3.96)\end{array}$ & $\begin{array}{c}8.57 \\
(8.34)\end{array}$ \\
\hline $\begin{array}{c}(4) \\
\mathrm{ZnL}\left(\mathrm{H}_{2} \mathrm{O}\right)_{2}\end{array}$ & dia & 4 & black & $>300$ & 48 & $\begin{array}{c}64.66 \\
(64.93)\end{array}$ & $\begin{array}{c}4.61 \\
(4.82)\end{array}$ & $\begin{array}{c}3.77 \\
(3.91)\end{array}$ & $\begin{array}{c}8.80 \\
(8.66)\end{array}$ \\
\hline
\end{tabular}

\subsection{NMR spectra}

The ${ }^{1} \mathrm{H}$ - and ${ }^{13} \mathrm{C}-\mathrm{NMR}$ spectra data of a DMSO- $d_{6}$ solution of the ligand HL show well-resolved signals as expected and can be given as follows: ${ }^{1} \mathrm{H}-\mathrm{NMR}$ : $6.49-7.67$ $(\mathrm{m}, 12 \mathrm{H}, \mathrm{Ar}-\mathrm{H}), 3.73\left(\mathrm{~s},{ }^{1} \mathrm{H},-\mathrm{OH}\right), 1.38\left(\mathrm{~s}, 3 \mathrm{H},-\mathrm{CH}_{3}\right)$, ${ }^{13}$ C-NMR (DMSO- $d_{6}$, ppm): 175.12 (imine), 116.13 148.93 (aromatic), 29.70 (aliphatic).

The ${ }^{1} \mathrm{H}-\mathrm{NMR}$ spectrum of the free ligand shows a multiplet in the range of $6.49-7.67 \mathrm{ppm}$ due to aromatic pro- tons. Also ${ }^{1} \mathrm{H}-\mathrm{NMR}$ spectrum of the HL shows a $\mathrm{D}_{2} \mathrm{O}$ exchangeable peak at $3.73 \mathrm{ppm}$ which is assigned to the aromatic $-\mathrm{OH}$ group. Furthermore, the singlet at $1.38 \mathrm{ppm}$ has been attributed to the protons of the methyl group.

The ${ }^{13} \mathrm{C}-\mathrm{NMR}$ of the ligand $\mathrm{HL}$ shows peaks at range 116.13-148.93 ppm, which are assignable to the carbons of the aromatic rings. The chemical shift of HL for imine carbon $(\mathrm{C}=\mathrm{N})$ was found at $175.12 \mathrm{ppm}$. The carbon atom of the methyl group was observed at $29.70 \mathrm{ppm}$ 
<smiles>CC(=Nc1ccc(Cl)cc1)N(O)c1cc(Cl)ccc1O/N=C(\C)c1ccc(-c2ccccc2)cc1</smiles>

Fig. 1. Proposed structure for the metal complexes of the ligand. $[\mathrm{M}=\mathrm{Co}(\mathrm{II}), \mathrm{Ni}(\mathrm{II}), \mathrm{Cu}(\mathrm{II}), \mathrm{Zn}(\mathrm{II})]$.

for $\mathrm{HL} .{ }^{1} \mathrm{H}$ - and ${ }^{13} \mathrm{C}-\mathrm{NMR}$ spectra data of the ligand in DMSO- $d_{6}$ confirm the proposed structure of the ligand (HL) (Fig. 1).

\subsection{IR spectra}

FT-IR data of the ligand and its complexes are given in Table II. The infrared spectrum of the ligand (HL) shows a $\nu(\mathrm{C}=\mathrm{N})$ peak at $1605 \mathrm{~cm}^{-1}$ and the absence of a $\nu(\mathrm{C}=\mathrm{O})$ peak at around $1700 \mathrm{~cm}^{-1}$ is indicative of formation of condensation reaction. The broad band for the -OH group at $3317 \mathrm{~cm}^{-1}$ observed in the IR spectra of the free ligand is absent in the IR spectra of their metal complexes, indicating deprotonation of the $\mathrm{OH}$ group and formation of $\mathrm{M}-\mathrm{O}$ bond. This is supported by the appearance of a new band in the region $517-552 \mathrm{~cm}^{-1}$ assigned to $\nu(\mathrm{M}-\mathrm{O})[8,9]$.

TABLE II

Significant bands in the IR spectra of the ligand and its metal complexes $\left(\mathrm{cm}^{-1}\right)$.

\begin{tabular}{c|c|c|c|c|c|c}
\hline \hline Compound & $\mathrm{O}-\mathrm{H}$ & $\mathrm{C}=\mathrm{N}$ & $\mathrm{C}-\mathrm{N}$ & $\mathrm{C}-\mathrm{O}$ & $\mathrm{M}-\mathrm{O}$ & $\mathrm{M}-\mathrm{N}$ \\
\hline $\mathrm{HL}$ & $3317 \mathrm{~s}$ & $1605 \mathrm{~s}$ & $1416 \mathrm{~s}$ & $1227 \mathrm{~s}$ & - & - \\
$\mathrm{CoL}\left(\mathrm{H}_{2} \mathrm{O}\right)_{2}$ & $3441 \mathrm{~b}$ & $1588 \mathrm{~m}$ & $1495 \mathrm{~s}$ & $1234 \mathrm{~m}$ & $552 \mathrm{w}$ & $444 \mathrm{w}$ \\
$\mathrm{NiL}\left(\mathrm{H}_{2} \mathrm{O}\right)_{2}$ & $3448 \mathrm{~b}$ & $1591 \mathrm{~m}$ & $1481 \mathrm{~s}$ & $1253 \mathrm{w}$ & $517 \mathrm{w}$ & $437 \mathrm{w}$ \\
$\mathrm{CuL}\left(\mathrm{H}_{2} \mathrm{O}\right)_{2}$ & $3414 \mathrm{~b}$ & $1590 \mathrm{~m}$ & $1502 \mathrm{w}$ & $1234 \mathrm{~s}$ & $527 \mathrm{w}$ & $440 \mathrm{w}$ \\
$\mathrm{ZnL}\left(\mathrm{H}_{2} \mathrm{O}\right)_{2}$ & $3448 \mathrm{~b}$ & $1593 \mathrm{w}$ & $1488 \mathrm{~m}$ & $1246 \mathrm{w}$ & $541 \mathrm{w}$ & $423 \mathrm{w}$ \\
\hline
\end{tabular}

b: broad, s: strong, m: medium, w: weak

The IR spectra of the mononuclear $\mathrm{Co}(\mathrm{II}), \mathrm{Ni}(\mathrm{II})$, $\mathrm{Cu}$ (II) and $\mathrm{Zn}$ (II) complexes also showed a broad band in the $3414-3448 \mathrm{~cm}^{-1}$ region, in line with the presence of water molecules coordinated to the metal ion [8].

The IR spectra of the metal complexes show bands between 1588 and $1593 \mathrm{~cm}^{-1}$ which indicates $\nu(\mathrm{C}=\mathrm{N})$ [10] and it is found that the $\nu(\mathrm{C}=\mathrm{N})$ bands in the complexes are shifted by $17-12 \mathrm{~cm}^{-1}$ to lower energy regions compared to the free ligand. This phenomenon appears to be due to the coordinated of azomethine nitrogens to the metal ion $[11,12]$.
The coordination mode of the ligand is further supported by new frequencies occurring in the $423-444 \mathrm{~cm}^{-1}$ ranges, which have been assigned tentatively to $\nu(\mathrm{M}-\mathrm{N})$.

\subsection{Thermogravimetric analysis}

The thermal decomposition behaviours of the ligand (HL) and its metal complexes were followed up to $1000{ }^{\circ} \mathrm{C}$ in nitrogen atmosphere. The thermal decomposition of the ligand (HL) with the molecular formula $\left[\mathrm{C}_{20} \mathrm{H}_{16} \mathrm{ClNO}\right]$ proceeds with three main degradation steps. The first step occurs within the temperature range $100-230^{\circ} \mathrm{C}$ with an estimated mass loss $68.00 \%$ (calculated mass loss $=68.75 \%$ ) which is reasonably accounted for the loss of one biphenyl, $\mathrm{CH}_{3},-\mathrm{Cl}$ and $-\mathrm{OH}$ groups. The second step occurs within the temperature range $230-480^{\circ} \mathrm{C}$ with an estimated mass loss $23.10 \%$ (calculated mass loss $=23.22 \%$ ), which is reasonably accounted for the loss of one benzene group. The third estimated mass loss of $8.50 \%$ (calculated mass loss $=8.30 \%$ ) within the temperature range $480-980^{\circ} \mathrm{C}$ could be attributed to the liberation of one $\mathrm{CN}$ group. Total estimated mass loss is $7.95 \%$ (calculated mass loss $=8.03 \%$ ).

The thermal decomposition of all synthesized complexes occurred in the similar manner. Because of this only thermogravimetric results of $\mathrm{Ni}(\mathrm{II})$ complex of $\mathrm{HL}$ are given. The thermal decomposition of the complex (2) with the molecular formula $\left[\mathrm{NiL}_{2}\left(\mathrm{H}_{2} \mathrm{O}\right)_{2}\right]$ also proceeds with four main degradation steps. The first estimated mass loss of $5.00 \%$ (calculated mass loss $=4.90 \%$ ) within the temperature range $105-140{ }^{\circ} \mathrm{C}$ could be attributed to the liberation of two $\mathrm{H}_{2} \mathrm{O}$ groups. The DTG curve gives a peak at $110^{\circ} \mathrm{C}$. The second step occurs within the temperature range $135-165^{\circ} \mathrm{C}$ with an estimated mass loss $9.40 \%$ (calculated mass loss $=9.00 \%$ ), which is reasonably accounted for loss of two $\mathrm{Cl}$ groups. The third step corresponding to loss of two $-\mathrm{CH}_{3}$ and two biphenyl groups (calculated mass loss $=45.00 \%$ ), with estimated mass loss of $45.60 \%$, were found within the temperature range $165-560{ }^{\circ} \mathrm{C}$. The last step probably accounted for the decomposition of remaining part of the complex. But decomposition did not finish at $1000^{\circ} \mathrm{C}$. Therefore, last decomposition residue was not determined.

\subsection{Magnetic susceptibility}

The magnetic moment values of the complexes have been measured at room temperature and are listed in Table I. The magnetic susceptibility measurements show that the complexes except $\mathrm{Zn}$ (II) complex (4) are paramagnetic at ambient temperature. According to the magnetic moment results $\mathrm{Co}$ (II) complex (1) has a room temperature magnetic moment of $3.80 \mathrm{BM}$ as expected for a high-spin octahedral Co(II) complex [13]. Synthesized $\mathrm{Ni}(\mathrm{II})$ complex (2) is paramagnetic with a magnetic susceptibility value of $2.88 \mathrm{BM}$, which is in agreement with the two-spin value of $2.83 \mathrm{BM}$. The magnetic moment data of the $\mathrm{Cu}(\mathrm{II})$ complex (3) at room temperature is ca. $1.87 \mathrm{BM}$, corresponding to one unpaired electron. The complex (3) may be considered to have octahedral geometry. 


\subsection{UV-Vis measurements}

The electronic spectra data of the ligand (HL) and its metal complexes are summarized in Table III. The UVvis spectra of the ligand exhibits 3 main peaks: at 295, 327 , and $316 \mathrm{~nm}$. The first and second peaks were attributed to $\pi \rightarrow \pi^{*}$ transitions of the benzene and imine group, respectively. The first peak of the ligand was not significantly affected by chelation. But the second peak was shifted to a shorter wavelength $(16-57 \mathrm{~nm})$. These shifts may be attributed to the chelation of the nitrogen atom of the ligand to the metal ion. It is further supported by the shifting the peak at $316 \mathrm{~nm}$ to a longer wavelength which was attributed to the $n \rightarrow \pi^{*}$ transitions.

TABLE III

UV-Vis absorption band data of the ligand and its complexes $(\mathrm{nm})$.

\begin{tabular}{c|c|c|c|c|c}
\hline \hline Compounds & $\begin{array}{c}\pi \rightarrow \pi^{*} \\
\text { (benzene) }\end{array}$ & $\begin{array}{c}\pi \rightarrow \pi^{*} \\
\text { (imine) }\end{array}$ & $n \rightarrow \pi^{*}$ & $\begin{array}{c}\text { Charge } \\
\text { transfer }\end{array}$ & $d \rightarrow d$ \\
\hline $\mathrm{HL}$ & 295 & 327 & 316 & - & - \\
$\mathrm{CoL}_{2}\left(\mathrm{H}_{2} \mathrm{O}\right)_{2}$ & 298 & 276 & 334 & 443 & 503 \\
$\mathrm{NiL}_{2}\left(\mathrm{H}_{2} \mathrm{O}\right)_{2}$ & 295 & 311 & 352 & 412 & 506 \\
$\mathrm{CuL}_{2}\left(\mathrm{H}_{2} \mathrm{O}\right)_{2}$ & 298 & 270 & 342 & 439 & 503 \\
$\mathrm{ZnL}_{2}\left(\mathrm{H}_{2} \mathrm{O}\right)_{2}$ & 295 & 303 & 330 & 421 & -
\end{tabular}

Another difference observed in the electronic spectra of the metal complexes, compared to the spectra of the corresponding free ligand, is associated with the appearance of a broad low intensity band at $c a .500 \mathrm{~nm}$. This band is attributed to the $d-d$ transitions of the metal ions. The appearance of a strong band between 412 and $443 \mathrm{~nm}$ is assigned to charge transfer bands.

\subsection{Conductivity measurements}

The conductances of the solutions of the complexes in DMF $\left(10^{-3} \mathrm{M}\right)$ are shown in Table I. As can be seen from Table I, the molar conductances of the complexes are between 4 and $17 \Omega^{-1} \mathrm{~cm}^{2} \mathrm{~mol}^{-1}$ indicating the nonelectrolytic nature of the complexes [14].

\subsection{Dye decolorization studies}

The catalytic activities of the complexes were evaluated in the decolorization of methylene blue at room temperature. Methylene blue shows several interesting features as a probe molecule for oxidation reactions, such as: (i) high solubility in water, (ii) the oxidation can be monitored simply by spectrophotometric measurements, and (iii) it simulates the behavior of textile dyes which are an important class of contaminant [15]. Experimental results show that $\mathrm{Cu}$ (II) complex (3) shows maximum decolorization at $25^{\circ} \mathrm{C}$.

The order of reactivity of the metal complexes is: $3>1>2>4$ (Fig. 3 ). It is believed that metal ion oxidized to hydrogen peroxide forming hydroxyl radical. Then the hydroxyl radical reacted with the methylene blue to oxidize it.

\section{Conclusion}

4-chloro-2-[1-(4-phenylphenyl)ethylideneamino]phenol ligand and its mononuclear $\mathrm{Co}(\mathrm{II}), \mathrm{Ni}(\mathrm{II}), \mathrm{Cu}(\mathrm{II})$, and $\mathrm{Zn}(\mathrm{II})$ complexes were synthesized and characterized by elemental analyses, magnetic susceptibility, molar conductivity, ${ }^{1} \mathrm{H}$ - and ${ }^{13} \mathrm{C}-\mathrm{NMR}$, FT-IR, UV-Vis, ICP-OES and TG-DTG (thermogravimetric-differential thermogravimetric) analysis studies. Elemental analyses, stoichiometric and spectroscopic data of the metal complexes indicated that in the complexes, metal ion was complexed with nitrogen atom of imine group and phenolic oxygen (Fig. 2). Metal complexes of the ligand have a 1:2 metal:ligand ratio and all complexes of the ligand have octahedral geometry. Furthermore, the rate of catalytic decolorization of methylene blue using prepared metal complexes was successfully performed. The dye has been successfully decolorized $91 \%$ in the presence of $\mathrm{Cu}(\mathrm{II})$ complex $(3)$ at $25^{\circ} \mathrm{C}$.

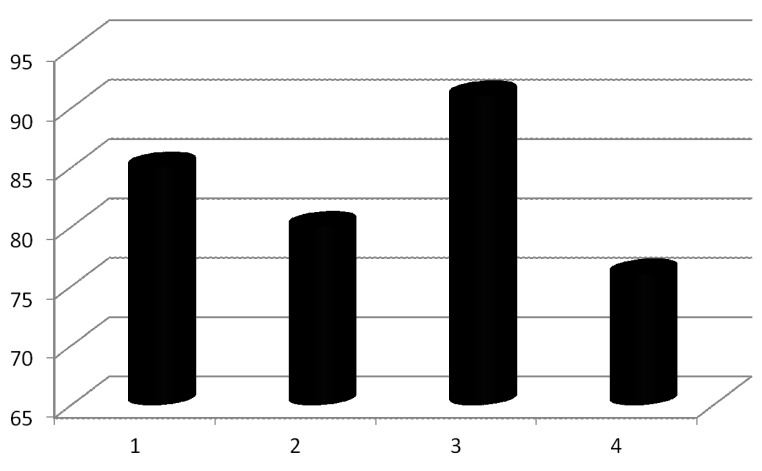

Fig. 2. Dye decolorization percentages of the metal complexes.

\section{References}

[1] M. Negoiu, S. Pasculescu, T. Rosu, R. Georgescu, C. Draghici, Rev. Chim. (Bucharest) 61, 762 (2010).

[2] A. Nishinaga, T. Yamada, H. Fujisawa, K. Ishizaki, H. Ihara, T. Matsuura, J. Mol. Catal. 48, 249 (1988).

[3] Y. Hamada, IEEE Trans. Electron Devices 44, 1208 (1997.

[4] A.I. Hanafy, A.K.T. Maki, M.M. Mostafa, Transition Met. Chem. 32, 960 (2007).

[5] I. Arslan, I.A. Balcioglu, T. Tuhkanen, D. Bahnemann, J. Environ. Eng. 126, 903 (2000).

[6] S.K. Chaudhuri, B. Sur, J. Environ. Eng. 126, 583 (2000).

[7] N. Levin, W.H. Hartung, J. Org. Chem. 7, 408 (1942).

[8] M. Gaber, M.M. Ayad, Y.S.Y. El-Sayed, Spectrochim. Acta, Part A 62, 694 (2005).

[9] N.M. Shauib, A.A. Elassar, A. El-Dissouky, Spectrochim. Acta, Part A 63, 714 (2006). 
[10] G. Das, R. Shukla, S. Mandal, R. Singh, P.K. Bharadwaj, J. van Hall, K.H. Whitmire, Inorg. Chem. 36, 323 (1997).

[11] C.A. McAuliffe, R.V. Parish, F.M. Ashmawy, R.M. Issa, S.A. Amer, J. Chem. Soc. Dalton Trans. 1987, 2009 (1987).

[12] I.A. Kahwa, J. Selbin, T.C.Y. Hsieh, R.A. Laine, Inorg. Chim. Acta 118, 179 (1986).
[13] M.M.H. Khalil, M.M.Mashaly, Chin. J. Chem. 26, 1669 (2008).

[14] W.J. Geary, Coord. Chem. Rev. 7, 81 (1971).

[15] F. Magalhaes, F.C.C. Moura, J.D. Ardisson, R.M. Lago, Mater. Res. 11, 307 (2008. 